\title{
El tiempo en la poética de Antonio Machado ${ }^{1}$
}

\author{
Juan Antonio SÁNCHEZ \\ Universidad Carolina de Praga
}

\begin{abstract}
Para Juan Sánchez Usero.
Lo que le ha costado convencerme.
\end{abstract}

\begin{abstract}
RESUMEN
El tiempo es uno de los elementos clave de la poética de Antonio Machado, como atestiguan numerosos estudios. Este elemento puede ponerse en relación con Bergson, filósofo que ejerce una importante influencia sobre el poeta de la generación del 98. En relación con esta influencia pueden entenderse los apócrifos machadianos como originados en la imposibilidad de la aprehensión de la vida de la consciencia que se deriva de la durée bergsoniana. Sin embargo, se propone en este estudio que el problema, tal y como Machado lo trata, supera los límites tanto del bergsonismo como del simbolismo para adentrarse en el ámbito de la crítica de la metafísica propuesta por Nietzsche y Heidegger, aunque en Machado no se encuentre sistematizada.
\end{abstract}

Palabras clave: Machado, Bergson, Metafísica, tiempo, poética, Nietzsche, Heidegger, durée.

\begin{abstract}
Time is one of the key elements of Antonio Machado's poetry, as plenty of studies show. This element can be related to Bergson, who strongly influenced the poet of the generation of 1898. According to this influence, it is possible to understand the poet's "apócrifos" as a response to the bergsonian imposibility of knowing the own life of the conscience. This impossibility follows as a concequence of the aplication of the concept of "durée". But, as this study tries to show, in Machado this topic exceeds the limits of symbolism and bergsonism to entry a different plateau: the critique of Metaphysics, as it was developed by Nietzsche and Heidegger, even if in Machado such critique does not appear systematically.
\end{abstract}

Keywords: Machado, Bergson, Metaphysics, Time, Poetic, Nietzsche, Heidegger, durée.

Según se mire, la afirmación de Machado de que "poesía es palabra esencial en el tiempo" puede parecer un enigma o una cosa obvia. Una cosa obvia: ¿qué

\footnotetext{
${ }^{1}$ Tento výstup vznikl v rámci projektu 'Problém času v humanitních a sociálních vědách' řešeného na Filozofické fakultě Univerzity Karlovy v Praze z prostředků specifického vysokoškolského výzkumu na rok 2010 pod číslem 261107.
} 
palabra, producida por el hombre bajo cualquier condición y en cualquier circunstancia, no es "en el tiempo"? ¿qué poesía no es "palabra esencial" o no se ocupa de la "esencia" de las cosas? Un enigma: ¿"esencial" se opone a "tiempo"? ¿"en el tiempo" significa "dentro" del tiempo, "con la misma calidad" que el tiempo, "parado" en el tiempo, etc? ¿qué implicaría concebir la "palabra" como "tiempo"? ¿qué es el "tiempo"?

Podemos encontrar la forma más aquilatada de esta famosa definición en la "Poética" que escribió el autor para la Antología de la poesía española, dirigida por Gerardo Diego. ${ }^{2}$ Pero hay otras que, para complicar el asunto, van componiendo unas como variaciones sobre un tema central, cada una de las cuales variaciones puede ser entendida con un matiz diferente. En ocasiones, por ejemplo, se propone el tiempo como el impulso existencial del que nace la necesidad de poesía:

[...] ¿cantaría el poeta sin la angustia del tiempo, sin la fatalidad de que las cosas no sean para nosotros, como para Dios, todas a la par, sino dispuestas en serie y encartuchadas como balas de rifle, para dispararlas una tras otra? ${ }^{3}$

A partir de este texto es muy fácil deducir que el tiempo debe ser el tema de la poesía. Puesto que la experiencia de la temporalidad es fundamental en la vida del hombre, de una forma u otra siempre se alude a ella. Según lo cual, la "palabra esencial en el tiempo" en tanto que poética podría entenderse en el sentido de que el tiempo es la motivación, la fuente, de donde surge lo poético -podría añadirse que también lo humano- y también la meta a donde se dirige: es la cosa, el asunto, de lo que la poesía habla. Es decir, habría que interpretar la fórmula poesía = palabra esencial en el tiempo en tanto que "palabra esencial sobre el tiempo -que es lo esencialmente humano." De la importancia del tiempo como tema de la poesía de Machado han hablado diversos críticos. ${ }^{4}$ De la motivación existencial del tema también. ${ }^{5}$ Pero en mi opinión, y teniendo en cuenta la dificultad y la oscuridad del pensamiento machadiano, la clave de su poética va más allá de lo que parece sugerir la idea de que el tiempo es sólo el tema de su poesía.

Con todo, ciertos comentarios de Machado o de sus apócrifos respaldan la dimensión "temática" del tiempo en su poética, añadiéndole además un matiz complementario. El poeta no sólo habla del tiempo, porque, como podemos deducir, es la experiencia básica de su humanidad, sino que lo eterniza:

2 A. Machado, (1989), p. 1802: "En este año de su Antología (1931) pienso, como en los años del modernismo literario (los de mi juventud), que la poesía es la palabra esencial en el tiempo." Merece la pena insistir en que, según el autor, no se trata sólo de un convencimiento actual, sino que según él mismo dice, era también el de su juventud.

${ }^{3}$ A. Machado, (1989), p. 1936.

${ }^{4}$ R. L. Predmore (1948), p. 701; B. Sesé, (1990), pp. 240 y ss.

${ }^{5}$ A. Sánchez Barbudo, (1981), pp. 370 y ss. 
El poeta pretende, en efecto, que su obra trascienda de los momentos psíquicos en que es producida. Pero no olvidemos que, precisamente, es el tiempo (el tiempo vital del poeta con su propia vibración) lo que el poeta pretende intemporalizar, digámoslo con toda pompa: eternizar. ${ }^{6}$

Como se ha comentado, se insiste aquí, al igual que en las notas de preparación para el discurso de ingreso en la Academia, en que el tiempo al que se refiere el poema es el tiempo real, vivido y concreto del poeta. ${ }^{7}$ El poeta pretende, según este fragmento, eternizar la experiencia cotidiana del tiempo. Este impulso de eternizar lo temporal es, a mi juicio, misterioso. Si a lo que aspira la lírica es a "intemporalizar" el tiempo, entonces la palabra esencial trataría el tema del tiempo dejando aparte lo más esencial que tiene el tiempo mismo, la temporalidad, y fracasando en su intento de captar lo más inherentemente humano, la experiencia de esa temporalidad. Según posible lectura de este fragmento, entonces, habría que entender la fórmula poética de Machado como "palabra esencial $-\mathrm{O}$ sea, intemporalizadora- sobre el tema del tiempo". Pero creo que si la leemos así, nos estamos alejando de su significado más sugerente. Y parece que el mismo Juan de Mairena/Antonio Machado desmiente esta lectura en las páginas que siguen al fragmento citado.

Allí su autor opone las soluciones contrarias que dan Manrique y Calderón a la llamada de la temporalidad lírica. Los dos hablan del tiempo, pero sólo le parece válido, o le parece más válido, el ejemplo de Manrique. La clave, por tanto, no puede estar en el tema. No se trata de hablar del tiempo, sino de cómo hablar. Palabra esencial en el tiempo es una fórmula que, a mi entender, tiene cuatro elementos fundamentales: palabra, esencial, en, y tiempo. "Esencial" parece corresponderse en ese fragmento con la pretensión de intemporalización aludida, pero esto nos llevaría a la paradoja de un tiempo destemporalizado.

De todas formas, no puede decirse que esa función eternizadora del arte aparezca sólo excepcionalmente en las reflexiones del autor. Así que no la podemos dejar de lado. En el cuaderno de notas conocido como Los complementarios, en la hoja 148v aparece un apunte, posiblemente fechable hacia 1924, que dice así:

Es evidente que la obra de arte aspira a un presente ideal, es decir, a lo intemporal. Pero esto de ninguna manera quiere decir que pueda excluirse el sentimiento de lo temporal en el arte. La lírica, por ejemplo, sin renunciar a su pretensión a lo intemporal, debe darnos la sensación estética del fluir del tiempo,

\footnotetext{
${ }^{6}$ A. Machado (1989), p. 697.

${ }^{7}$ J. López Morillas (1947), p. 116; J. Villegas (1965), p. 448.
} 
es precisamente el flujo del tiempo, uno de los motivos líricos, que la poesía trata de salvar del tiempo, que la poesía pretende intemporalizar. ${ }^{8}$

Según esto, la pretensión de la lírica sería una intemporalización de lo temporal. Se corre el peligro de empezar a jugar trivialmente con las palabras. Pero no sólo; queda explícito además un impulso contradictorio, quizá esencialmente contradictorio, de lo poético e incluso puede que del lenguaje mismo. Y, de todas formas, no son esas todas las variaciones sobre la "poética de la temporalidad" debidas a Machado; está claro que era algo que obsesionaba al escritor. En su Juan de Mairena, hay una curiosa: "Ya en otra ocasión definíamos la poesía como diálogo del hombre con el tiempo [...]." ¿A qué tiempo se refiere en este fragmento?

Parece que al tiempo propio de cada hombre, a su propia temporalidad concreta e histórica, ya que poco después pone al "poeta puro" como ejemplo negativo porque habla con $s u$ tiempo vaciándolo para hacer de esa conversación una especie de monólogo. El poeta puro, que Machado tanto criticó, no dialoga con el tiempo: monologa. Marra el tiempo real de cada individuo. Consecuentemente la clave no parece encontrarse en que se trate el tema del tiempo, como decía antes, sino en cómo se trata. Se puede tratar con el tiempo como un "poeta puro", concepto con el que Machado hacía referencia a la constelación Juan Ramón-Valéry-Guillén, y, por extensión, a los componentes de la generacion del 27, o sea como poeta "deshumanizado"; o bien puede hacerse como poeta humanizado. ${ }^{10} \mathrm{La}$ forma de "monologar" con el tiempo de los poetas puros era, para Machado, y a pesar del respeto e incluso amistad que les profesaba $-\mathrm{y}$ ellos a él- demasiado conceptual, podría decirse que demasiado atemporal:

Hoy como ayer conceptistas y culteranos tienen el concepto, no la intuición, por denominador común. Cuando leemos a algún poeta de nuestros días -recordemos a Paul Valéry entre los franceses, a Jorge Guillén entre los españoles -buscamos en su obra la línea melódica trazada sobre el sentir individual. No la encontramos. Su frigidez nos desconcierta $y$, en parte, nos repele. ${ }^{11}$

Recordemos que antes citábamos el fragmento en el que Machado prefería a Manrique frente a Calderón, es decir al medieval -aunque las Coplas de Manrique no son precisamente un típico ejemplo de poesía cancioneril- frente al barroco. Sin embargo, los jóvenes poetas del 27 prefieren el barroco, sobre todo a Góngora, el

\footnotetext{
${ }^{8}$ A. Machado (1989), p. 1312. En la misma página: "Lo intemporal es la obra de arte, no lo representado en ella: en este caso, el fluir del tiempo."

9 A. Machado (1989), p. 1937; Subrayado mío. R. de Zubiría (1969), pp. 25 y ss.

${ }^{10}$ Emplea el concepto de "deshumanización”, citando a Ortega, en la página 1938.

${ }^{11}$ A. Machado (1989), p. 1791.
} 
poeta más "puro" de su tiempo. Parece, entonces, que lo que Machado "rechaza" es, por tanto, una determinada realización y concepción del lenguaje lírico en su diálogo con la temporalidad; la clave está en el cómo del diálogo con el tiempo o del lenguaje sobre o por el tiempo. ¿Será todo una cuestión de estilo? Creo que hay algo más que eso. Palabra esencial en el tiempo es una fórmula, yo diría más enigmática que sencilla, que nos empuja al análisis de la palabra, de su esencialidad, del tiempo y sobre todo del en.

A la hora de dilucidar la importancia de la dimensión temporal en la poética de Machado suele aducirse abundantemente la influencia de Bergson. En más de una ocasión, el poeta cita explícitamente al filósofo francés, como por ejemplo en la nota autobiográfica compuesta para la Antología de Gerardo Diego: "De Soria a París (1910). Asistía a un curso de Henri Bergson en el Colegio de Francia."12

Parece, desde luego, indudable, que las obras del filósofo francés juegan un papel destacado en la formación intelectual del poeta español. ${ }^{13}$ Pero los límites, sentido y alcance de esa recepción no están definitivamente aclarados. Por ejemplo, en opinión de Glendinning, en Machado "only the idea of things in Time, as opposed to subject to it, is truly Bergsonian, and there are relatively few of Machado's poems which deal with this aspect of time in plainly philosophical terms." 14

La clave del bergsonismo de Machado radica en su atención a la vida fluctuante de la conciencia, morfología cualitativa e integradora de la experiencia fenomenológica, en tanto que estructura originaria de la individualidad, irreductible a esquemas cuantitativos. Esa experiencia es, además, esencialmente temporal -la durée; pero su temporalidad no puede ser medida con los relojes, operación únicamente posible si se concibe el tiempo espacialmente -porque sólo en el espacio es posible el número.

\footnotetext{
12 A. Machado (1989), p. 1802. Machado hizo el viaje a Francia con una beca, y lo acompañó Leonor. También asistió a un curso de Bédier. Cf. J. M. Valverde (1986), pp. 8485. En el cuaderno Los complementarios desarrolla esa información: "Durante el curso 1910 a 1911 asistí a las lecciones de Henri Bergson. El aula donde daba su clase era la mayor del Colegio de Francia y estaba siempre rebosante de oyentes. Bergson es un hombre frío, de ojos muy vivos. Su cráneo es muy bello. Su palabra es perfecta, pero no añade nada a su obra escrita. Entre los oyentes hay muchas mujeres.": Antonio Machado (1989), p. 1159. Cf. también C. Clavería (1945), p. 171.

${ }^{13}$ Así lo atestiguan numerosos estudios; entre ellos, X. Tilliete (1962); A. Sánchez Barbudo (1981) y sobre todo E. Frutos (1960).

${ }^{14}$ N. Glendinning (1962), p. 51.
} 
Lorsque nous parlons du temps, nous pensons le plus souvent à un milieu homogèn où nos faits de conscience s'alignent, se juxtaposent comme dans l'espace, et réussissent à former une multiplicité distincte. Le temps ainsi compris ne serait-il pas à la multiplicité de nos états psychiques ce que l'intensité est à certains d'entre eux, un signe, un symbole, absolument distinct de la vraie durée? ${ }^{15}$

Consecuencia: el tiempo interno -el único que hay- del yo es un flujo pululante de vivencias, percepciones y rememoraciones que se integran unas en otras formando un todo indistinguible e inasequible a la explicación racional. ${ }^{16}$ Sólo puede alcanzarse a través de la intuición, según Bergson, que, en Machado, se correspondería en un primer momento con el simbolismo como intento de captación de la interioridad. ${ }^{17}$ Un intento condenado al fracaso.

En realidad, la vida interior, la durée, es inabarcable e incomprensible; no podemos captarla, no podemos conceptualizarla. Es la vida originaria de la psique, que sólo puede ser vivida. Cuando tornamos a ella encontramos ya otra cosa. ${ }^{18}$ Los recuerdos de nuestros propios estados de consciencia no son sino construcciones modificadoras de experiencias originarias que no pueden volver. De ahí, la eterna pregunta - sin respuesta- de Machado por el pasado apócrifo y su fascinación por el laberinto de la memoria y del ahora:

[...] Ya soy más viejo que eras tú, padre mío, cuando me besabas.

Pero en el recuerdo, soy también el niño que tu llevabas de la mano.

¡Muchos años han pasado sin que yo te recordara, padre mío!

¿Dónde estabas tú en esos años? ${ }^{19}$

${ }^{15}$ H. Bergson (1936), p. 69.

${ }^{16}$ H. Bergson (1936), p. 79: "Bref, la pure durée pourrait bien n'être qu'une succession de changements qualitatifs qui se fondent, qui se pénètrent, sans contours précis, sans aucune tendance à s'exterioriser les unes par rapport aux autres, sans aucune parenté avec le nombre: ce serait l'hétérogénéité pure."

${ }^{17}$ E. Frutos (1960), p. 127: "Hay dos tipos de multiplicidad [...]: una, la de los objetos materiales, numerables; y otra, la de los fenómenos de conciencia, que no se pueden medir sino simbólicamente." Y más abajo: "La duración pura es inefable..."

${ }^{18}$ Nunca vemos al "sujeto", que es la actividad contemplativa, nunca lo contemplado: A. Machado (1989) CLXI: "El ojo que ves no es / ojo porque tú lo veas, / es ojo porque te ve." Es vano intentar alcanzar el conocimiento profundo de la interioridad de los otros, lo mismo que la de sí. Cf. XXVIII-XIX de Juan de Mairena, en A. Machado (1989), pp. 2022-2023.

${ }^{19}$ A. Machado (1989), p. 784. Se corresponde con el poema escrito en el cuaderno de Los Complementarios, 22r y lleva la fecha del 13 de marzo de 1916. Cf. A. Machado (1989), p. 1182-3. 
La pregunta por la realidad de los sentimientos y de la vida psíquica es constante en Machado, desde Soledades hasta Nuevas canciones. Sin embargo, hay que ponerle una limitación a esa concentración solipsista en el yo fundamental, que, como se ha dicho, demuestra una propincuidad con el pensamiento del filósofo francés. En opinión de Frutos, la intuición como forma de alcanzar la vida verdadera de la consciencia no es suficiente para Machado que introduce un elemento nuevo en el problema: el tú. ${ }^{20}$ Es decir, que la pregunta que preocupa al poeta es, sí, la inefabilidad del yo fundamental, pero también la inefabilidad del mundo que está enfrente.

Por tanto, volviendo al tema de la temporalidad en su poética, no podemos reducirlo a los límites del bergsonismo, por muy importante que sea éste en la formación de de Machado. La ecuación bergsonismo-simbolismo, si es que puede considerarse como acertada, ${ }^{21}$ no da la medida de la totalidad de la poética machadiana. Así es como pretende explicarla, por ejemplo, Aguirre. Según su propuesta, Machado seguiría la estela de lo que ya hacían los poetas franceses de fines del XIX. ${ }^{22}$ Para este crítico, el poema "expresa" la temporalidad en el sentido de que "la presenta" ante los ojos del lector. Esta es su interpretación del número XI de Soledades, "Yo voy soñando caminos". 23 Mediante un sistema de pausas, se evoca el paso del tiempo psicológico: el texto mismo es como la fluctuación inaprehensible de nuestra consciencia mientras se alude a la llegada de la tarde. Pero esta sugerente lectura implicaría ver el tiempo, en tanto que elemento poético, como algo representado por el lenguaje. Mediante unos u otros dispositivos retóricos, se nos da una imagen de lo que es el tiempo. En este sentido, poesía no sería "palabra esencial en el tiempo", sino "acerca del tiempo", "figurando el tiempo" o "que representa el tiempo". La pregunta sería entonces ¿desde dónde lo hace? Creo que Machado no quería representar el tiempo. ${ }^{24}$ El tiempo es algo irrepresentable; sólo

${ }^{20}$ E. Frutos (1960), pp. 133 y ss.; E. Barjau (1971), pp. 68 y ss.; A. Sánchez Barbudo (1981), pp. 334-5, donde se habla de la "insatisfacción con el puro intuicionismo bergsoniano". Hay que tener en cuenta el tono irónico de Machado hacia Bergson: "Este Bergson es un tuno", del Poema de un día. Cf. A. Machado (1989), p. 555.

${ }^{21}$ Para una crítica de dicha ecuación, cf. M. Blanchot (1949). Sobre el simbolismo como intento de lengua perfecta y la relación entre simbolismo y Bergson: E. Voldřichová Beránková (2006).

${ }^{22}$ J. M. Aguirre (1973), pp. 111 y ss.

${ }^{23}$ J. M. Aguirre (1973), pp. 125 y ss.

${ }^{24}$ Cf. las dudas de Juan de Mairena acerca del mismo acto de representar en A. Machado (1989), pp. 1915-16: "La palabra representación, que ha viciado toda la teoría del conocimiento -habla Mairena en clase de Retórica-, envuelve muchos equívocos, que pueden ser funestos para el poeta. Las cosas están presentes en la consciencia o ausentes de ella. No es fácil probar, y nadie, en efecto, ha probado que estén representadas en la conciencia. [...] A vosotros, que vais para poetas, artistas imaginadores, os invito a meditar sobre este tema. Porque también vosotros tendréis que habéroslas con presencias y 
puede vivirse. ${ }^{25}$ El tiempo es el problema del poeta, es aquello con lo que el poeta está constantemente en contacto sin saber qué es, como un interrogante que no se soluciona. El poema no surge como posible respuesta, como resultado de una contemplación, ni mucho menos como una teoría o una hipótesis. El poeta no quiere "dar una impresión de tiempo" como si estuviera informándonos, porque no sabe lo que es. El poema surge de la experiencia de la ignorancia más fundamental:

Han cegado mis ojos las cenizas

del fuego heraclitano.

El mundo es, un momento,

transparente, vacío, ciego, alado. ${ }^{26}$

Esta experiencia, desde luego, no se reduce a la primera etapa de su obra, sino que se extiende por toda ella, marcándola profundamente con su sello, y podemos suponer que acompañó al poeta toda su vida. Pero esta pregunta, para Machado no resuelta, Bergson, a su modo, parecía resolverla con la intuición, mediante la cual podía establecerse un contacto con la vida psíquica y con la durée. ${ }^{27}$ Machado en cambio, como se ha dicho, insatisfecho con el simbolismo, con el intuicionismo, y con el solipsismo que implican, abre los horizontes de su pregunta hacia el tú.

El problema de la temporalidad en Machado no puede reducirse a una representación de la inefable durée bergsoniana. La relación de su poética con Bergson no sería directa, sino oblicua: acoge los términos del problema pero no su solución: el problema del conocimiento del yo le lleva a plantearse el del conocimiento del otro y a dirigirse hacia sí mismo como a un "otro" inaprehensible. La pregunta por el yo fundamental, incluso en la primera época de Soledades, implica ya esa postura. El poeta se dirige a su interior sin poder afirmar su propia realidad individual, como si estuviera enfrente de sí mismo - de ahí la constante estructura de diálogo de muchos de sus poemas. Pero el tú al que se abre el poeta no

ausencias, de ningún modo con copias, traducciones ni representaciones." También se puede aducir el siguiente texto del mismo libro para mostrar las dudas de Machado ante una actividad poética "traductora" o "expresadora" de la consciencia o de las cosas: "Todavía más gedeónico -por no decir más absurdo- me parece el pensar que nuestra conciencia traduce a su propia lengua un mundo escrito en otra; porque si esta otra lengua le es desconocida, mal puede traducir, y si la conoce, ¿para qué traduce? Mejor diríamos: ¿para quién?” En A. Machado (1989), p. 1999.

${ }^{25}$ Podría aludirse aquí a El ser y el tiempo, donde Heidegger advierte que el tiempo no es un ente: "La temporalidad no «es», en general, un ente. No es, sino que se «temporacía»", en M. Heidegger (2001), § 65, p. 356. Versión alemana en M. Heidegger (1977), p. 328. "Die Zeitlichkeit «ist» überhaupt kein Seiendes. Sie ist nicht, sondern zeitigt sich."

${ }^{26}$ A. Machado (1989), p. 615. Pertenece a la última sección del poema "Galerías", de Nuevas canciones (1917-1930)

${ }^{27}$ Ver el primer capítulo de G. Deleuze (1998). 
es sólo el prójimo, los otros hombres -aunque también- sino todo objeto de conocimiento, el mundo entero. El tú es lo objetivo, lo no inmanente, también el propio yo cuando se reflexiona sobre él. Esta constatación está en la base de su poetica. No hay una tesis, expuesta desde la individualidad, sobre la inefabilidad de ésta. Precisamente a causa de la inefabilidad de la durée, lo que se sabe, o sea, lo que se manifiesta en el lenguaje, no es lo mismo, sino lo otro. En el lenguaje, el yo y el mundo se manifiesta continuamente como lo otro. Por eso Machado, partiendo de presupuestos poéticos que se mantienen desde su primera época, aborda el fenómeno de la escritura como el de la manifestación de la otredad: la consecuencia lógica es el fenómeno de los apócrifos.

La primera manifestación de los apócrifos, o complementarios, aparece, según Oreste Macrí, ${ }^{28}$ en el cuaderno conocido precisamente con ese nombre, Los complementarios, y está datada en Sevilla, 1914. Se trata de una coplilla firmada por un tal Abel Infanzón:

¡Oh maravilla!

Sevilla sin sevillanos, ¡la gran Sevilla! ${ }^{29}$

Después aparecen José María Izquierdo y un texto ("Pensar: vaciar el huevo") ${ }^{30}$ que se reintegrará después en el soneto "Al gran Cero" de Abel Martín, incluido en De un cancionero apócrifo, ${ }^{31}$ aunque en la página $10 \mathrm{v}$ de Los complementarios el nombre de Abel Martín todavía no aparece. Luego le sigue una nómina no de poetas apócrifos, sino de ensayistas apócrifos, y ya en la página 105r del cuaderno la primera lista de 10 poetas. En páginas sucesivas se añaden otros apócrifos, poetas y ensayistas, entre los cuales se encuentra por ejemplo un tal Antonio Machado, que

[...] nació en Sevilla en 1875. Fue profesor en Soria, Baeza, Segovia y Teruel. Murió en Huesca en fecha todavía no precisada. ${ }^{32}$

Los más conocidos son, sin duda, Abel Martín y su discípulo, Juan de Mairena. Estamos en el año 1923; casi diez antes Pessoa inventaba a Alberto Caeiro y su discípulo, Álvaro de Campos. Pero Machado tiene lo que no tiene el portugués: un

${ }^{28}$ O. Macrí (1989), p. 74.

${ }^{29}$ A. Machado (1989), p. 1157.

${ }^{30}$ A. Machado (1989), p. 1164.

${ }^{31}$ A. Machado (1989), p. 693.

${ }^{32}$ A. Machado (1989), pp. 1270-1271. 
apócrifo inventado por un apócrifo: Jorge Meneses, creación de Juan de Mairena. Finalmente, existe un apócrifo, Pedro de Zúñiga, del que tenemos noticia por una carta de 1928 a Giménez Caballero. ${ }^{33}$ En total, Macrí cuenta nada menos que 34 apócrifos: "cinco ensayistas, seis filósofos y veintitrés poetas." "34

La cuestión de los apócrifos no es sencilla. Para Abellán, la función del apócrifo es la de captar con la imaginación (en oposición a la lógica o la razón) lo que está oculto en la consciencia. La creación de apócrifos sería, entonces, una técnica hacia el inconsciente, hacia las capas ocultas y misteriosas de la personalidad del poeta. ${ }^{35}$ Para Barjau, el apócrifo sirve como técnica de espejos concéntricos, un sistema de máscaras que tiende a abarcar la infinita multiplicación y riqueza de la individualidad, y lo relaciona con el fenómeno de la ironía romántica. ${ }^{36}$ Para Laitenberger, Abel Martín es una proyección autorreflexiva de la propia poética de Machado en el periodo de las Soledades ${ }^{37}$ mientras que Mairena representaría la tendencia más temporalista del mismo poeta, y se identificaría con la creación de Campos de Castilla y Nuevas canciones. ${ }^{38}$ Es decir, que ambos apócrifos representarían facetas diferentes de una misma poética, la del creador de carne y hueso; poetas filósofo (frente a los poetas poeta de Pessoa) que expresan el fundamento teórico de la lírica de Machado. Estas lecturas son sin duda interesantes, pero abordan el fenómeno de los apócrifos desde una perspectiva psicológica: los conceptualizan en tanto que mecanismo de expresión de la psique. Es decir, como artificios retóricos bajo los cuales hay una sola personalidad, máscaras que ocultan, pero por eso mismo también dejan ver, una $c a r a .{ }^{39}$ Es decir, se trata de una interpretación del apócrifo machadiano que sigue una línea romántica. Sin embargo, creo que puede leerse con otra clave; es lo que ha hecho más recientemente el profesor Cerezo Galán. Si los apócrifos fueran un intento de abarcar la totalidad cambiante y pululante de la personalidad, su finalidad habría sido la de alcanzar una expresividad absoluta de la profundidad del yo. Pero ni el

\footnotetext{
${ }^{33}$ A. Machado (1989), p. 1759.
}

${ }^{34}$ O. Macrí (1989), p. 77.

${ }^{35}$ J. L. Abellán (1979), pp. 77-83 y (1989). Una posible crítica a la interpretación de Abellán de lo apócrifo según su sentido etimolótico de "oculto", "profundo" y por ello "imaginario", puede encontrarse en H. Laitenberger (1972), p. 157.

${ }^{36}$ E. Barjau (1974). Existe un libro del mismo autor, Antonio Machado: teoría y práctica del apócrifo, que reproduce ese artículo y otros ensayos, pero que no he podido conslutar. D. Ynduráin (1986) va mas o menos en esta dirección, pero con vislumbres interesantísimos que se comentarán seguidamente.

${ }^{37}$ H. Laitenberger (1972), p. 130.

${ }^{38}$ H. Laitenberger (1972), p. 158.

39 Así lo sugiere por ejemplo la siguiente afirmación de mi querido profesor E. Barjau (1974), p. 105: "Lo apócrifo es, ante todo lo pensado, lo imaginado, lo que salta por encima de lo real, pero esto pensado e imaginado tiende muchas veces a ocultarse, hay que irlo a buscar en secretos repliegues de nuestro yo." Subrayado mío. 
tono ni el contenido de los apócrifos parecen perseguir esta meta: “[...] como hubiera dicho Mairena, no hay en Machado rastro de una pretensión de absoluto, que mantuviera en vilo una voluntad infinita de trascendimiento. $"{ }^{40}$

La escritura del apócrifo -como en Pessoa la de los heterónimos- no pretende construir un todo, sino que es más bien el testimonio de una experiencia originaria de fragmentación. ${ }^{41}$ No persigue una síntesis, sino que se deleita en la contradicción y el desfondamiento de la experiencia de eso a lo que con un constructo se alude como "persona". Cuenta con la falta de fundamento de la vida de la consciencia y no quiere superarla. ${ }^{42}$ Se mantiene en esas arenas movedizas heraclíteas, mirando como se hunde lentamente. Precisamente el pensamiento de uno de los apócrifos más conocidos, Juan de Mairena, profesor de gimnasia y retórica, es un constante ejercicio de autocrítica y contradicción. No para alcanzar una verdad más profunda, sino más bien en la experiencia de la reversibilidad de toda verdad. Se diría que se trata de una especie de escepticismo ante la misma posibilidad de la verdad y de su papel en la vida del hombre:

Contra los escépticos se esgrime un argumento aplastante: «Quien afirma que la verdad no existe, pretende que eso sea la verdad, incurriendo en palmaria contradicción». Sin embargo, este argumento irrefutable no ha convencido, seguramente, a ningún escéptico. Porque la gracia del escéptico consiste en que los argumentos no le convencen. Tampoco pretende él convencer a nadie. ${ }^{43}$

Si cada consciencia es diferente, una mónada aíslada de las otras, según preconiza Abel Martín, es imposible encontrar un criterio para la verdad común. De ello se deduce que las experiencias de los individuos, o las del mismo individuo en momentos diferentes, en el momento de la opinión y el de la reflexión, son siempre heterogéneas:

\footnotetext{
${ }^{40}$ P. Cerezo Galán (1994), p. 187.

${ }^{41}$ P. Cerezo Galán (1994), p. 188: "Se vuelve, pues, del revés, el principio romántico de una subjetividad infinita, y en su lugar aparece un yo fragmentario, disperso y heteróclito, que no puede establecerse, ni siquiera en un movimiento infinito, como universo integral de consciencia."

${ }^{42}$ A. Machado (1989), p. 1192: “[...] ¿para qué sirve la inteligencia? Para colocarnos fuera de lo real, para crearnos un mundo aparencial, ficticio y en el cual no sabemos como podríamos vivir. No puede, pues, estar al servicio de la vida." Se encuentra en las páginas que dedica al bergsonismo y corresponde a Los complementarios, $28 \mathrm{r}$.

${ }^{43}$ A. Machado (1989), p. 1913. (De Juan de Mairena). A. Sánchez Barbudo llama a esta tendencia del pensamiento machadiano "apasionado escepticismo"; cf. A. Sánchez Barbudo, (1981), p. 279.
} 
La verdad es la verdad, dígala Agamenón o su porquero.

Agamenón. Conforme.

El Porquero. No me convence. ${ }^{44}$

O, como comenta en su cuaderno Los complementarios: "Nunca estoy más cerca de pensar una cosa que cuando he escrito la contraria". ${ }^{45}$ No radica esta inestabilidad del pensamiento en la llamada heterogeneidad del ser, de la que tanto habla Abel Martín? En esta dirección parece que va la propuesta de Valverde, hecha casi como sin pensar, y donde yo encuentro lo más interesante que se ha escrito sobre los apócrifos machadianos. Comentando el hecho de que en la lista de apócrifos de Los complementarios aparece un apócrifo Antonio Machado, dice: "La broma de hacerse auto-apócrifo, desdoblándose en un «futurible» con traslado a Teruel y muerte en Huesca, acaso expresa la nueva conciencia de que, en el fondo, toda poesía es apócrifa y requiere la previa creación de un personaje dramático en cuya boca tenga su enmarque adecuado [...]." ${ }^{.46}$

¿Quién soy yo?, se pregunta el poeta ya en su primera época de Soledades. Respuesta: no puedo saberlo. Partiendo de un punto concomitante con el bergsonismo, advierte que la vida de la consciencia es inalcanzable, inconceptualizable: "la inteligencia es incapaz de pensar lo vivo". Es decir, incapaz de pensar el yo fundamental, inútil para el autoconocimiento. La pregunta que una y otra vez retorna en Soledades inquiere vanamente por la persona que hay dentro del alma, y lo único que ve es un fantasma borroso:

Para buscar tu queja de tus labios

yo te busqué en tu sueño,

y allí te vi vagando en un borroso

laberinto de espejos. ${ }^{48}$

Pero lo que vemos en esa primera etapa de Soledades no es sólo una tematización bergsoniana de la imposibilidad de autoconocimiento de la vida interior de la consciencia. Es una experiencia originaria no un tema que plantea (¿quién lo plantea?) el poeta. Sería contradictorio que ese yo fundamental, que no se sabe

${ }^{44}$ A. Machado (1989), p. 2131.

${ }^{45}$ A. Machado (1989), p. 1188. Curiosamente recuerda al siguiente fragmento del Silvestre Paradox: "Silvestre estaba tan acostumbrado a la soledad, que hablaba solo o a lo más con el perro, con la avutarda disecada, o con la culebrilla. Sus observaciones, aun en la calle, las hacía a media voz, no con la idea de que le oyesen, sino para discutirlas. Había notado que las ideas de uno mismo, expresadas en palabras, suenan a ideas de otro y dan ganas sólo por eso de no aceptarlas y de discutirlas.” En P. Baroja (1973), p. 116.

${ }^{46}$ J. M. Valverde (1986), p. 174. Subrayado mío.

${ }^{47}$ A. Machado (1989), p. 1192. De Los complementarios, 27v.

${ }^{48}$ A. Machado (1989), p. 451. 
quién es, expresara o pusiera como tema su propia carencia de fundamento. Lo que aparece ya en esta primera época es la experiencia originaria del yo como otro. El lógico desarrollo es la creación de los apócrifos, que no forman un dispositivo de la individualidad para expresarse mejor o para conocerse mejor, sino que ponen en escena el único comportamiento posible del lenguaje después de la experiencia de la otredad del yo. Debajo de la máscara del apócrifo no hay una cara. Antonio Machado es también una máscara, como el mismo poeta sugiere al incluirse a sí mismo como futurible en la nómina. En el espacio de la propia producción conviven diversas voces porque lo distintivo de la individualidad es la multiplicidad:

Pero además, ¿pensáis - añadía Mairena- que un hombre no puede llevar dentro de sí más de un poeta? Lo difícil sería lo contrario, que no llevase más que uno. ${ }^{49}$

Si toda actividad intelectual (y la poesía, en tanto que ejercicio del lenguaje, lo es) es esencialmente apócrifa, si nuestro mundo interior es una construcción imaginaria desvinculada o desacoplada de una posible y nunca experimentada verdad trascendente, todo poema es apócrifo y toda escritura es la de un autor que es inventado por el propio poema o que hay que inventar para inventar luego que ese poeta inventado escribe el poema:

Vivimos en un mundo esencialmente apócrifo, en un cosmos o poema de nuestro pensar, ordenado o construido todo él sobre supuestos indemostrables, postulados de nuestra razón, que llaman principios de la lógica, los cuales, reducidos al principio de identidad que los resume y reasume a todos, constituyen un solo y magnífico supuesto: el que afirma que todas las cosas, por el mero hecho de ser pensadas, permanecen inmutables, ancladas, por decirlo así, en el río de Heráclito. ${ }^{50}$

No tiene sentido, consecuentemente, entender la temporalidad de la poética machadiana como un ejercicio de conocimiento, de comunicación de un contenido a

\footnotetext{
49 A. Machado (1989), p. 1995. De Juan de Mairena.

50 A. Machado (1989), p. 1998. De Juan de Mairena. Podrían aducirse otros textos que problematizan la noción romántica del autor. Por ejemplo, A. Machado (1989), p. 2015: "Las obras poéticas realmente bellas, decía mi maestro -habla Mairena a sus discípulos-, rara vez tienen un solo autor. Dicho de otro modo: son obras que se hacen solas, a través de los siglos y de los poetas, a veces a pesar de los poetas mismos, aunque siempre, naturalmente, en ellos" o A. Machado (1989), p. 2023: "Pero ¿y el nosce te ipsum, la sentencia délfica? ¿A qué puede obligarnos ya ese imperativo? He aquí lo verdaderamente grave del problema. Si la ciencia del conocimiento de sí mismo, que Sócrates reputaba única digna del hombre, pasa a saber de especialistas, estamos perdidos. Dicho en otra forma: ¿cómo podrás saber algo de ti mismo si de esa materia, como de todas las demás, es siempre otro el que sabe algo?"
} 
la mano del poeta; como expresión de la profunda verdad de la vivencia temporal la durée; como la participación y entrega por la palabra de algo que el individuo ha encontrado dentro de sí mismo -en las galerías del alma. El que tenía la pluma en la mano se encontraba, desde los comienzos de su trayectoria, con ese laberinto de espejos de la heterogeneidad del ser -aunque al principio fuera con ayuda de Bergson- y su desarrollo posterior dependió orgánicamente de los mismos presupuestos que fomentaron sus primeras intuiciones. ${ }^{51}$ Tiempo, heterogeneidad del ser, búsqueda del tú y apócrifos son manifestaciones paralelas del mismo fenómeno: la experiencia de la inconsistencia y mutabilidad del mundo y de uno mismo.

No estoy de acuerdo con la forma que tiene el profesor Frutos de interpretar la heterogeneidad del ser en Machado. Por una parte limita la heterogeneidad a su aspecto antropológico: el yo tiende siempre hacia el tú, quiere ser el tú, y por eso no se concuerda sencillamente con lo que es, pierde estabilidad; su esencia sería, según él, el desplazamiento hacia el otro. ${ }^{52}$ La marcha hacia el tú sería, por tanto, un salto que se hace hacia lo heterogéneo mediante el amor. El amor se entiende, consecuentemente, como la marca que tiene el fenómeno de la heterogeneidad en el pensamiento machadiano, y como el único "método" de alcanzar el exterior del yo y salir del solipsismo. Una especie de alternativa a la inmanencia de la razón. ${ }^{53}$

Sin duda que, según Machado, la experiencia del amor aboca al individuo a encarar un tú que no sea hipóstasis o proyección de la propia vida psíquica. Y por eso le obliga a entrar en un diálogo con sus semejantes; dialogo en el que lo básico es estár dispuesto por lo menos a intentar reconocer en el otro un "sujeto", incluso con las contradicciones que esto implica. Pero no puede decirse que para él "heterogeneidad del ser" se reduzca sólo a eso. Una prueba son los mismos apócrifos. Ni siquiera Abel Martín, que es el que trata más extensamente el tema del amor, se limita al mismo. En su filosofía, el hombre no está abocado únicamente al

51 A esa heterogeneidad del yo alude Ynduráin en relación con la estructura dialogada de algunos poemas de Soledades; cf. D. Ynduráin (1986), pp. 355 y ss. Este crítico cita un trabajo de E. Barjau (1981) que, desgraciadamente, tampoco he podido consultar.

52 E. Frutos (1959), p. 280: "La esencial heterogeneidad del ser está vista en el plano antropológico, no en el ontológico." Barjau (1971), p. 68, se centra en el amor como vía hacia el otro. Tampoco estoy de acuerdo con la interpretación de M. Siguán (1987), p. 275: "La otredad del hombre consiste por tanto en que para alcanzar la plenitud ha de llegar a ser otro en el doble sentido de que ha de llegar a ser «otro», distinto de como es, y ha de llegar a serlo en «otro»." Machado no busca al otro para alcanzar la plenitud.

${ }^{53}$ E. Frutos (1960), p. 134: "[Machado] intenta superar el solipsismo a que la intuición de su propio yo le conduce. Y el camino no es la razón universal, sino el amor: un «universal del sentimiento»." 
otro, sino a lo otro, como explica Sánchez Barbudo. ${ }^{54}$ Por otra parte, en el caso de Mairena, vemos que la heterogeneidad a la se remite es de orden cognoscitivo y ontológico y afecta en todos sus aspectos al diálogo del hombre con las cosas. La consciencia no se enfrenta a su otro sólo cuando tiene enfrente a un tú, sino también un mundo. En la misma concepción de "verdad" que tiene Mairena encontramos la marca, la huella, de la heterogeneidad del ser:

Nadie debe asustarse de lo que piensa, aunque su pensar aparezca en pugna con las leyes más elementales de la lógica. Porque todo ha de ser pensado por alguien, y el mayor desatino puede ser un punto de vista de lo real. Que dos y dos sean necesariamente cuatro, es una opinión que muchos compartimos. Pero si alguien necesariamente piensa otra cosa, que lo diga. ${ }^{55}$

Pero tampoco se mantiene Mairena en un nivel meramente gnoseológico. No se alude sólo a un problema del conocimiento, a la imposibilidad de conectar la conciencia con las cosas que son. Abandona la concepción metafísica que piensa la cosa en tanto que lo uno:

Que toda cosa sea igual a sí misma no es, ni mucho menos, una verdad averiguada por la vía discursiva, ni tampoco una evidencia o intuición de lo real, sino un supuesto necesario al artificio o mecanismo de nuestro pensamiento, el cual supuesto, de puro imprescindible para razonar, nos parece verdadero. ${ }^{56}$

Me parece innegable que Machado estaba en contacto con algunos de los problemas que se planteaban en el debate filosófico europeo de su época. No sólo lo demuestra su atención a Bergson, sino más allá. Podríamos encontrar aquí quizá ecos del perpectivismo de Ortega, con quien, como se sabe, estudiaba filosofía en la universidad central, pero también existen ciertos paralelismos con el pensamiento de Nietzsche, ${ }^{57}$ y pronto hablaré de su curiosa recepción de Heidegger. La

\footnotetext{
${ }^{54}$ A. Sánchez Barbudo (1954), pp. 47 y ss. En la p. 47 cita un fragmento de Abel Martín que es esclarecedor a este respecto: "El hombre quiere ser otro. He aquí lo específicamente humano ... su mónada solitaria no es nunca pensada como autosuficiente, sino como nostálgica de lo otro, paciente de una incurable alteridad." Dicho fragmento puede encontrarse en A. Machado (1989), p. 2097, correspondiente a Juan de Mairena, XLIV. ${ }_{55}^{5}$ A. Machado (1989), p. 2028. Corresponde a Juan de Mairena, XXX.

${ }^{56}$ A. Machado (1989), p. 2033. Corresponde a Juan de Mairena, XXXI.

${ }^{57}$ Discernir el signo de la recepción, las similitudes y las diferencias con respecto al autor del Zarathustra va más allá de la intención de este artículo. Pero podrían sugerirse diversos temas compartidos: la crítica o relativización del concepto de verdad, aunque en el español sea sin un rendimiento ontológico; cf. A. Machado (1989), p. 2034: "Es evidente, decía mi maestro - cuando mi maestro decía es evidente, o no estaba seguro de lo que decía, o sospechaba que alguien pudiera estarlo de la tesis contraria a la que él proponía [...]"; la
} 
heterogeneidad del ser machadiana, en este marco, adquiere proporciones mucho más amplias que las planteadas por el problema amoroso. El ser es heterogéneo porque sucede en el tiempo, en incesante transferencia de lo uno a lo otro. Nuestra relación con las cosas o con nosotros mismos se da con la dinámica de esa transferencia: nunca conocemos algo como ello mismo, sino como dado a mí en un momento determinado. Por eso Martín rechaza presupuestos poéticos que pudieran ser reducidos a bergsonismo, interpretado como expresividad de la vida íntima de la consciencia:

Cuando se preguntaba a Martín si la poesía aspiraba a expresar lo inmediato psíquico, pues la conciencia, cogida en su propia fuente, sería, conciencia integral, respondía: «Sí y no. Para el hombre, lo inmediato consciente es siempre cazado en el camino de vuelta $[\ldots]\rangle^{58}$

Ser no implica unidad. No sólo porque cada uno vea la "cosa en sí" de forma diferente. Si la cosa puede ser pensada como sí misma y su contrario es porque el ser mismo, en su característica más inherente, persiste como alteridad. Las cosas o la conciencia no se aparecen nunca como algo absoluto. Son (aunque creo que Machado no llega tan lejos como a negar la "cosa en sí") siempre sólo en un momento concreto, y luego desaparecen y ya son otras. La presencia del ser como alteridad es posible precisamente porque vivimos en el tiempo. O quizá "tiempo" sea la conceptualización de la experiencia originaria de esa alteridad. Quizá, en el pensamiento machadiano, heterogeneidad y temporalidad son las dos caras de la misma moneda.

Creo que, al menos en un corte de la producción de Machado -dudo de que pueda ser una fórmula aplicable a toda su obra- "palabra en el tiempo" no significa "palabra que representa al tiempo" sino uso de la palabra en el espacio que le es más propio: la temporalidad concreta. Y porque al hombre le es tan inherente esa misma temporalidad, su palabra es "esencial", no anecdótica. Machado decía que Soledades era acaso el primer libro del que está prescrito lo anecdótico ${ }^{59}$ ¿Cuál es la diferencia entre lo anecdótico y lo "esencialmente temporal"? Lo anecdótico es

problematización de la ética (aunque Machado se mueva en muchos momentos dentro de una ética entre Kantiana y cristiana); cf. A. Machado (1989), p. 2021: "Habréis reparado [Mairena a sus alumnos] en que casi nunca os hablo de moral, tema retórico por excelencia. Y es que [...] la moral no es mi fuerte. Y no porque sea yo un hombre más allá del bien y del mal, como algunos lectores de Nietzsche [...], sino precisamente por todo lo contrario: por no haber salido nunca, ni aun en sueños, de ese laberinto de lo bueno y de lo malo, de lo que está bien y de lo que está mal [...]”; y por último la ya mencionada crítica de la metafísica y la consiguiente crítica de la noción de sujeto como fundamento de la verdad, de la que se viene hablando en estas páginas.

${ }^{58}$ A. Machado (1989), p. 688. Correspondiente a De un cancionero apócrifo, CLXVII.

${ }^{59}$ A. Machado (1989), p. 1207. Correspondiente a Los complementarios, 42r. 
aquello que, habiendo sucedido una vez, pierde su propio carácter específico, único, para convertirse en "representativo" o "ejemplificador", se convierte en un "caso", está concebido como una objetividad. Pero la vivencia del tiempo sucede una vez y no vuelve nunca, en eso reside su carácter enigmático y precioso, y sucede como actividad, no como algo "percibido". No es recuperable, lo anecdótico sí. Creo que Machado se esforzaba por escribir a partir de la experiencia, misteriosa y escurridiza, del tiempo concreto y de su flujo constante. En su primera época, priva el simbolismo, y después busca una expresión cada vez más directa. Pero hay una tendencia que es común a ambas: el poema aparece, a menudo, como "acto enunciativo" no como "obra terminada". Como se ha visto, en Soledades es abundante el diálogo. Hay una estética simbolista, sin duda, pero sus símbolos están, digamos, en proceso performativo, a menudo a través de formas diversas del diálogo, como ya se ha mencionado, de un uso comunicativo, dramático, del lenguaje. Por ejemplo el diálogo consigo mismo:

[...] dije, y después, declamatoriamente:

- ¡Cuán tarde ya para la dicha mía!-

Y luego, al caminar, como quien siente

alas de otra ilusión: -Y todavía

¡yo alcanzaré mi juventud un día! ${ }^{60}$

la evocación y el vocativo

Vosotras, las familiares $[\ldots]^{61}$

la lectura:

Quiso el poeta recordar a solas,[...]

Leyó $[\ldots]^{62}$

la glosa

Nuestras vidas son los ríos

que van a dar a la mar,

que es el morir. ¡Gran cantar! ${ }^{63}$

Y podría seguirse con el diálogo en sueños, como LXIII y muchos otros; el diálogo dramático con personajes más o menos ficticios, como con la muerte del LIV; la apelación a las cosas, como en el XLIII, el LIX o en el LXXVI; a su propio corazón, como el LX; la escritura hipotética, como el LXVII; el discurso con el yo como si

${ }^{60}$ A. Machado (1989), p. 464, L.

${ }^{61}$ A. Machado (1989), p. 462, XLVIII.

${ }^{62}$ A. Machado (1989), p. 463, XLIX.

${ }^{63}$ A. Machado (1989), p. 470, LVIII. 
fuera un tú, como los LXIX y LXX, etc. Pero además, hay muchos poemas que parten de una situación concreta, de un momento del paseo, de una parada para contemplar el paisaje, la escena, el desarrollo de las nubes, para oír las voces o para meditar sobre lo que pasa por la cabeza. Sólo como muestra, el maravilloso comienzo del número LXXVI:
¡Oh tarde luminosa!
El aire está encantado.
La blanca cigüeña
dormita volando,
y las golondrinas se cruzan, tendidas
las alas agudas al viento dorado, $\mathrm{y}$ en la tarde risueña se alejan volando, soñando... ${ }^{64}$

Esta localización concreta del discurso -pero no anecdótico, porque se hace a partir de la experiencia de la irreversibilidad del instante- continúa, con un lenguaje más sencillo, en Campos de Castilla:

Mediaba el mes de julio. Era un hermoso día.

Yo, solo, por las quiebras del pedregal subía. ${ }^{65}$

El poema tiene un desarrollo digamos dramático, y al final la tarde ha transcurrido:

El sol va declinando. De la ciudad lejana me llega un armonioso tañido de campana $[\ldots]^{66}$

Es común encontrarse con textos que recrean la misma situación de la que parten como enunciado y donde hay un diálogo constante de la voz con el mundo inmediato que la circunscribe:

$¡ \mathrm{Oh}$, Soria, cuando miro los frescos naranjales cargados de perfume, y el campo enverdecido, abiertos los jazmines, maduros los trigales, azules las montañas y el olivar florido; Guadalquivir corriendo al mar entre vergeles $[\ldots]^{67}$

${ }^{64}$ A. Machado (1989), p. 480.

${ }^{65}$ A. Machado (1989), p. 493, XCVIII.

${ }^{66}$ A. Machado (1989), p. 495.

${ }^{67}$ A. Machado (1989), p. 542, CXVI. El poema fue escrito en el tren en abril de 1913. 
Y podrían aducirse muchos otros textos en los que el lenguaje se presenta como enunciación en un tiempo concreto, como si se (re)creara el momento del diálogo directo del poeta con su mundo: por ejemplo CXXI, CXXVII, CXXVIII, CXXXII y luego en Nuevas canciones lo mismo

Hacia Madrid, una noche, va el tren por Guadarrama. ${ }^{68}$

o como carta o elogio, o sea, como palabra en acto de diálogo presente, por ejemplo los número CXXVI, CXLI, CXLIII, CXLIX. El lenguaje, en una gran parte de su producción poética, está "situado" y "temporalizado". Es lenguaje en acto, no resultado artesanal de lo que se hace con una materia llamada lenguaje. Según estas apreciaciones, podría decirse que el "tiempo" de la fórmula poética machadiana es el tiempo concreto de la vivencia, no sólo el de la durée, aunque también, sino el del lenguaje como forma de estar el hombre con las cosas en el marco del instante.

$\mathrm{Y}$ en este marco cobra sentido, precisamente, la atención que prestó Machado a Heidegger al final de su vida. Lo demuestra su ensayo sobre el filósofo alemán, escrito en Valencia en 1938 cuando el poeta huía de Madrid con toda la República desmoronándose. ${ }^{69}$ Puede que Machado no hubiera leído El ser y el tiempo, sino que habría utilizado el libro de Gurvitch, Las tendencias actuales de la filosofia alemana. Con todo, Sánchez Barbudo opina que, aunque se valiera de ese manual, el poeta pudo haber conocido la obra ${ }^{70}$ La gran pregunta es si Machado conocía el alemán como para poder leer a Heidegger. Recuérdese que la primera edición de Sein und Zeit es de 1927. No había traducciones.

Entre las muchas cosas interesantes que podemos encontrar en este estudio, hacia el final hay una oposición explícita de la concepción de la temporalidad en Bergson y en Heidegger:

Los que buscábamos en la metafísica una cura de eternidad, de actividad lógica al margen del tiempo, nos vamos a encontrar [...] definitiva y metafísicamente cercados por el tiempo. ¿Por una viva eternidad como la durée bergsoniana? Algo peor. El tiempo de Heidegger, su tiempo primordial, como en Bergson ajeno a toda cantidad, esencialmente cualitativo, es, no obstante, finito y limitado. ${ }^{71}$

\footnotetext{
${ }^{68}$ A. Machado (1989), p. 616, CLVIII. Puede añadirse la sección XI de CLXIV, "Sanatorio del alto Guadarrama."

${ }^{69}$ Fue publicado en el número XIII de Hora de España. Está en A. Machado (1989), pp. 2360-2368.

${ }^{70}$ A. Sánchez Barbudo (1981), p. 385.

${ }^{71}$ A. Machado (1989), p. 2367-8.
} 
Esta apreciación es, a mi entender, de importancia crucial. Aquí se manifiesta la comentada recepción y superación machadiana del bergsonismo. ¿Qué le falta a Bergson que sí se encuentra en Heidegger? El tiempo, en el análisis bergsoniano, no se entiende desde la perspectiva de la existencia concreta del hombre. Sin embargo, Machado se identifica, se encuentra a sí mismo, en el existencialismo. Cree reconocer la angustia heideggeriana (que, esta vez sí, Machado pudo conocer directamente por el trabajo Qué es metafísica, de Heidegger, traducido por Zubiri en $1933)^{72}$ en un poema suyo escrito en 1907, o sea, veinte años antes de que Heidegger, que era entonces profesor ayudante de Husserl en Friburgo, ${ }^{73}$ publicara su gran obra. Incluso cree detectarla en el mismo Unamuno. ${ }^{74}$

Machado siente como suya esta concepción existencialista del tiempo. Al final de su vida, al descubrir la obra de Heidegger, directa o indirectamente, reconocería en ella una propincuidad con su propio entendimiento del problema del tiempo. Se diría que el poeta ha ido orbitando, desde la década de 1910, de una posición más bergsonista a otra más existencialista. En ésta, el concepto de temporalidad es, definitivamente, limitado, concreto. El tiempo de Bergson fluye, pero no es, específicamente, aquello que se pierde. No es el tiempo de la criatura concreta, sino el tiempo de la mente de un hombre teórico. El tiempo no anecdótico ni absoluto de Machado también es el que fluye, llevando en su corriente a la conciencia, pero además, al fluir, deja sumido en la desolación de la pérdida:

¿Los yunques y crisoles de tu alma trabajan para el polvo y para el viento? ${ }^{75}$

El tiempo originario, en la exégesis heideggeriana, es, precisamente, finito; ${ }^{76} \mathrm{y}$, podría decirse que esta finitud es la que ha interesado a Machado en toda su obra.

${ }^{72}$ A. Sánchez Barbudo (1981), p. 385.

${ }^{73}$ A. Machado (1989), p. 2362.

74 A. Machado (1989), p. 2365. Machado no dice dónde, pero no sería difícil encontrar ejemplos, como este de Del sentimiento trágico de la vida (1986, p. 195): "La congoja es algo mucho más hondo, más íntimo y más espiritual que el dolor. Suele uno sentirse acongojado hasta en medio de eso que llamamos la felicidad y por la felicidad misma, a la que no se resigna y ante la cual tiembla." Sin que tengan el mismo valor, podrían establecerse ciertos paralelismos con el concepto heideggeriano de Angst.

${ }^{75}$ A. Machado (1989), p. 482, LXXVII.

${ }^{76}$ M. Heidegger (2001), § 65, p. 358: “El problema no puede formularse así: ¿cómo se convierte el tiempo infinito, derivado, «en que» surge y pasa lo «ante los ojos», en la temporalidad finita, original?, sino así: ¿cómo surge de la temporalidad propia y finita la impropia, y cómo temporacía ésta, en cuanto impropia, del tiempo finito otro in-finito? Sólo porque el tiempo original es finito puede temporaciarse el «derivado» como in-finito." Original en M. Heidegger (1977), pp. 330-331: "Das problem kann nicht lauten: wie wird die »abgeleitete« undendliche Zeit, »in der« das Vorhandene entsteht und vergeht, zur 
Palabra esencial en el tiempo, por tanto, deja leerse así: es la pronunciación de la palabra en el momento del estar el hombre, por medio de esta palabra, en el mundo, experimentando el movimiento originario de la heterogeneidad del ser en el desplazamiento de la temporalidad. Esa palabra no nos habla de quién la pronuncia, ya que no se sabe quién es, proyectando más bien que, en cualquier caso, se trata de una voz que pertenece siempre a otro. Y si es "esencial" no es porque persigue la construcción o el descubrimiento de un absoluto; sino porque se origina en la experiencia de la deuda, causada por el tiempo, en la experiencia de la pérdida (en la que se manifiesta la esencial heterogeneidad del ser). Es decir, es una vez y es irremplazable. Esa pérdida se da "esencialmente" en tanto que es lo que más íntimamente define al hombre -ese que no sabe de sí mismo quién es- ${ }^{77}$ es lo que le es inherentemente más propio. Palabra esencial en el tiempo es palabra en la desaparicion de las cosas en la temporalidad -en la que somos. Palabra que, precisamente en su renuncia al absoluto, (y Machado renunció a la búsqueda de la vida absoluta de la consciencia, du vecú, de l'absolu ${ }^{78}$ se puede transfigurar, superar el problema que tanto preocupaba a Abel Martín de la subjetividad y la objetividad y dedicarse, sencillamente, a nombrar las cosas, a ver el mundo con los ojos de la cara:

Supongamos por un momento que el hombre actual ha encontrado sus ojos, los ojos para ver lo real, a lo que nos referimos. Los tenía en la cara, allí donde ni siquiera pensó en buscarlos. Esto quiere decir que empieza a creer en la realidad

ursprünglichen endlichen Zeitlichkeit, sondern wie entspringt aus der endlichen eigentlichen Zeitlichkeit die uneigentliche, und wie zeitigt diese als uneigentliche aus der endlichen eine un-endliche Zeit? Nur weil die ursprüngliche Zeit endlich ist, kann sich die »abgeleitete« als un-endliche zeitigen."

${ }^{77}$ M. Heidegger (2001), § 5, p. 25: "Sin duda el «ser ahí» es ónticamente no sólo algo cercano o incluso lo más cercano -nosotros mismos somos en cada caso él. A pesar de ello, o justo por ello, es ontológicamente lo más lejano."; y § 63, p. 338: “El ente que somos en cada caso nosotros mismos es ontológicamente lo más lejano." Original en M. Heidegger (1977), § 5, p. 15: "Das Dasein ist zwar ontisch nicht nur nahe oder gar das nächste -wir sind es sogar je selbst. Trotzdem oder gerade deshalb ist es ontologisch das Fernste."; y $\S$ 63, p. 311: "Das Seiende, das wir je selbst sind, ist ontologisch das Fernste."

${ }^{78}$ En las páginas $27 \mathrm{r}$ y ss. de Los complementarios ya hay un intento de superación del bergsonismo, pero en ese tiempo, 1917, hacia un pensamiento racionalista y eleático; hacia una especie de fenomenología. Cf. A. Machado (1989), pp. 1190 y ss. Un deseo de ir más allá del intuicionismo simbolista-bergsoniano podemos hallarlo, por ejemplo, en el ensayo "El simbolismo", de 1922; Cf. A. Machado (1989), pp. 1637-38: "Lo inmediato psíquico, la intuición que pretende sugerir el poeta lírico de todos los tiempos, es algo, ciertamente, singular que vaga azorado en nuestro espíritu [...]. Pero esa nota sine qua non de todo poema necesita para ser expresada y reconocida el fondo de imágenes genéricas y familiares, sobre el cual destaque su singularidad, su vibración, única y momentánea." Subrayado mío. 
de cuanto ve y toca. El mundo como ilusión -piensa- no es más explicable que el mundo como realidad. [...] No soy ya el soñador, el frenético mimo de mi propio sueño. Tampoco el mundo se viste de máscara para que yo lo contemple. Las cosas están allí donde las veo, los ojos allí donde ven. Lo absoluto está para mí tan inabarcable como ayer. Pero mi relación con lo real es real también. ${ }^{79}$

La poética de la palabra esencial en el tiempo es la poética del ámbito transitorio en que al hombre le es dado usar la palabra para nombrar las cosas; una palabra que sólo sirve para una vez y que no conlleva ninguna verdad, entendida ésta como entidad útil más allá del caso concreto en el que la palabra resuena. En el tiempo, el hombre tiene un diálogo con las cosas y consigo mismo, diálogo que no tiene más sentido que el mismo de decir, una vez, las cosas, porque "Hier ist des Säglichen Zeit." ${ }^{" 80}$ En el marco de esa poética de la temporalidad, tiempo y heterogeneidad son dos manifestaciones de lo mismo, y palabra esencial no es dieferente a palabla "hablada", que no por ello pierde su esencialidad, sino justamente lo contrario. Lo esencial, aquí, es lo originario. La palabra que dialoga con el mundo nombrando las cosas en el flujo irreversible de la temporalidad es la palabra más "esencial" porque es la más "verdadera" manifestación del lenguaje:

Rehabilitemos a la palabra en su valor integral. Con la palabra se hace música, pintura y mil cosas más; pero sobre todo, se habla. ${ }^{81}$

Constatación estilísticamente paralela a la poética del alumno de Mairena que traducía a lenguaje poético diciendo "lo que pasa en la calle." 82

${ }^{79}$ A. Machado (1989), p. 1656-7.

${ }^{80}$ R. M. Rilke (1998), IX, v. 43, p. 144; literalmente: Aquí es el tiempo de lo decible.

${ }^{81}$ A. Machado (1989), p. 1657. Compárese con M. Heidegger (2001), § 34, pp. 178 y 179: "El fundamento ontológico-existenciario del lenguaje es el habla." "Hablar es articular «significativamente» la comprensibilidad del «ser en el mundo», al que es inherente el «ser con» y que se mantiene en cada caso en un modo determinado del «ser uno con otro», «curándose de». Éste, el «ser uno con otro», es «hablante»: da su palabra y retira la palabra dada, requiere, amonesta, sostiene una conversación, se pone al habla, habla en favor, hace declaraciones, habla en público." Original en M. Heidegger (1977), pp. 160 y 161: “Das existenzial-ontologische Fundament der Sprache ist die Rede." "Reden ist das «bedeutende» Gliedern der Verständlichkeit des In-der-Welt-seins, dem das Mitsein zugehört, und das sich je in einer bestimmten Weise des besorgenden Miteinanderseins hält. Dieses ist redend als zu- und absagen, aufforordern, warnen, als Aussprache, Rücksprache, Fürsprache, ferner als «Aussagen machen» und als Reden in der Weise des «Redenhaltens»."

${ }^{82}$ A. Machado (1989), p. 1909, pertenece, como se sabe, a Juan de Mairena I. 


\section{Obras citadas}

ABELLÁN, J. L.: «La filosofía de Antonio Machado y su teoría de lo apócrifo», $E l$ basilisco, 7 (1979), pp. 77-83.

- «El concepto de "apócrifo" en la filosofía de Antono Machado: su interés para el historiador», Ínsula, 506-507 (1989), pp. 2-3.

AGUIRRE, J. M.: Antonio Machado, poeta simbolista, Madrid, Taurus, 1973.

BARJAU, Eustaquio: «Antonio Machado: entre poesía y filosofía», Convivium, 35 (1971), pp. 49-75

- «Antonio Machado: teoría y práctica del apócrifo», Convivium, 43 (1974), pp. 89120.

- «Juan de Mairena: teoría del diálogo», Instituto de Bachillerato Cervantes, s/n (1981), pp. 247-264.

BAROJA, Pío: Aventuras, inventos y mixtificaciones de Silvestre Paradox, Madrid, Caro Raggio, 1973.

BLANCHOT, Maurice: «Bergson and symbolism», Yale French Studies, 4 (1949), pp. 63-66.

BERGSON, Henri: Essai sur les donées immédiates de la conscience, París, Félix Alcan, 1936.

CEREZO GALÁN, Pedro: «Lo apócrifo machadiano: "un ensayo de esfuerzos fragmentarios"» en Antonio Machado hoy, 1939-1989. Coloquio internacional organizado por la Casa de Velázquez, Madrid, Casa de Velázquez, 1994, pp. 185-207.

CLAVERÍA, Carlos: «Notas sobre la poética de Antonio Machado», Hispania, 28 (1945), pp. 166-183.

DELEUZE, Gilles: Le bergsonisme, París, PUF, 1998.

FRUTOS, Eugenio: «La esencial heterogeneidad del ser en Antonio Machado», Revista de filosofia, 69-70 (1959), pp. 271-292.

- «El primer Bergson en Antonio Machado», Revista de filosofía, 73-74 (1960), pp. 117-168.

GLENDINNING, Nigel: «The philosophy of Henri Bergson in the poetry of Antonio Machado», Revue de littérature comparée, 36 (1962), pp. 50-70.

LAITENBERGER, Hugo: Antonio Machado. Sein Versuch einer Selbstinterpretation in seinen Apokryphen Dichterphilosophen, Wiesbaden, Franz Steiner, 1972.

LÓPEZ MORILLAS, Juan: «Antonio Machado's temporal interpretation of poetry», The Journal of Aesthetics and Art Criticism, 6 (1947), pp. 161171.

HEIDEGGER, Martin: El ser y el tiempo, FCE, Madrid, 2001.

- Sein und Zeit, Tübingen, Max Niemeyer, 1977 (1927).

MACHADO, Antonio: Obras completas, Madrid, Espasa-Calpe, 1989.

MACRÍ, Oreste: "Introducción" a Antonio Machado, Obras completas, Madrid, Espasa-Calpe, 1989. 
PREDMORE, Richard L.: «El tiempo en la poesía de Antonio Machado», Papers of the Modern Language Asociation, 63 (1948), pp. 696-711.

RILKE, Rainer M.: Las elegías de Duino y otros poemas, Santiago de Chile, Editorial Universitaria, 1998.

SÁNCHEZ BARBUDO, Antonio: «El pensamiento de Abel Martín y Juan de Mairena en relación con la poesía de Antonio Machado», Hispanic Review, 22 (1954), pp. 32-74.

- Estudios sobre Galdós, Unamuno y Machado, Barcelona, Lumen, 1981.

SESÉ, Bernard: Claves de Antonio Machado, Madrid, Espasa-Calpe, 1990.

SIGUÁN, Miguel: «El tema del otro en Antonio Machado», Anuario de psicología, 1 (1987), pp. 33-52.

TILLIETE, Xavier: «Antonio Machado, poète philosophe», Revue de littérature comparée, 36 (1962), pp. 32-49.

VALVERDE, José M.: Antonio Machado, Madrid, Siglo XXI, 1986.

VOLDŘICHOVÁ-BERÁNKOVÁ, Eva: «A la recherche de la Langue perdue», en Acta universitatis Palackinae olomucensis. Facultas philosophica. Philologica 90-2006. Romanica XVII. Université d'été - Langue(s) et langages, Olomouc, Universidad Palacký de Olomouc, 2006. pp. 171-181.

VILLEGAS, Juan: «El tema del tiempo en un poema de Antonio Machado», Hispania, 48 (1965), pp. 442-451.

UNAMUNO, Miguel de: Del sentimiento trágico de la vida, Madrid, Alianza, 1986. YNDURÁIN, Domingo: «Los apócrifos de Antonio Machado (1902-1939) », Anuario de estudios filológicos, 9 (1986), pp. 349-362.

ZUBIRÍA, Ramón de: La poesía de Antonio Machado, Madrid, Gredos, 1969. 